\title{
Advanced Research on Dopamine Signaling to Develop Drugs for the Treatment of Mental Disorders: Ser311Cys Polymorphisms of the Dopamine $\mathrm{D}_{2}$-Receptor Gene and Schizophrenia
}

\author{
Masanari Itokawa ${ }^{1, *}$, Tadao Arinami ${ }^{2}$, and Michio Toru ${ }^{3}$ \\ ${ }^{1}$ Schizophrenia and Affective Disorders Research Project, Tokyo Institute of Psychiatry, \\ 2-1-8 Kamikitazawa, Setagaya-ku, Tokyo 156-8585, Japan \\ ${ }^{2}$ Department of Medical Genetics, Majors of Medical Sciences, Graduate School of Comprehensive Human Sciences, \\ University of Tsukuba, Laboratory of Advanced Research D, 1-1-1 Tennodai, Tsukuba, Ibaraki 305-8577, Japan \\ ${ }^{3}$ Department of Neuropsychiatry, School of Medicine, Tokyo Medical \& Dental University, \\ 1-5-45 Yushima, Bunkyo-ku, Tokyo 113-8510, Japan
}

Received April 20, 2010; Accepted June 21, 2010

\begin{abstract}
Schizophrenia is a debilitating and complex mental disorder with a prevalence of approximately $1 \%$ worldwide. The etiology remains unclear, despite massive research efforts. Hyperactive dopaminergic signal transduction in the central nervous system is suggested to be involved in the pathophysiology of schizophrenia (the dopamine hypothesis). The dopamine $\mathrm{D}_{2}-$ receptor $(D R D 2)$ gene is thus a promising candidate for associations with risk of schizophrenia. We investigated $D R D 2$ and found a novel missense nucleotide change causing an amino acid substitution of serine with cysteine at codon 311 (Ser311Cys). We performed an association study using 156 schizophrenia patients and 300 controls. Cys311 in DRD2 was significantly associated with schizophrenia. Patients with the Cys311 allele displayed shorter duration of hospitalization and less severe negative symptoms and were more frequently married compared to patients without this allele, suggesting good response to treatment. We expanded samples to 291 patients with schizophrenia (including 11 postmortem brain samples), 579 controls, and 78 patients with affective disorders in a further case-control study. Cys311 was associated with schizophrenia, particularly in patients without negative symptoms, and bipolar disorder with mood-incongruent psychotic symptoms. Three meta-analyses using over 20 published studies confirmed the association. In vitro studies showed that Cys311-type $\mathrm{D}_{2}$ receptor impairs dopamine-induced sequestration, which appears to be consistent with the dopamine hypothesis.
\end{abstract}

Keywords: schizophrenia, dopamine $\mathrm{D}_{2}$ receptor, association, Ser311Cys, sequestration

\section{Introduction}

Schizophrenia is a debilitating and complex mental disorder with a prevalence of approximately $1 \%$ worldwide. The etiology remains unclear, despite massive research efforts $(1,2)$. Hyperactive dopaminergic signal transduction in the central nervous system has been suggested to be involved in the pathophysiology of schizo-

*Corresponding author. itokawa-ms@igakuken.or.jp Published online in J-STAGE on August 12, 2010 (in advance) doi: 10.1254/jphs.10R07FM phrenia (dopamine hypothesis), based upon three lines of evidence. The first is that healthy subjects taking drugs such as methamphetamine and cocaine that increase dopamine levels in the brain exhibit schizophrenia-like psychotic symptoms (3). Second, the antipsychotic potencies of neuroleptic drugs correlate with affinities for the dopamine $\mathrm{D}_{2}$ receptor (4). Third, a large number of postmortem brain studies have suggested increased density of $\mathrm{D}_{2}$ receptors in the striatum of patients with schizophrenia $(5,6)$. A twin study estimated the heritability of schizophrenia as 0.80 , suggesting a relatively larger genetic contribution to development of the illness 
compared to that of other common diseases (e.g., high blood pressure, 0.30 ; obesity, $0.40-0.75)$ (7). The dopamine $\mathrm{D}_{2}$ receptor $(D R D 2)$ gene is thus a promising candidate for an association with disorder risk. Dopamine $\mathrm{D}_{2}$ receptors are a class of metabotropic $\mathrm{G}$ protein-coupled receptors that are prominent in the vertebrate central nervous system (CNS). It regulates not only the CNS but also the cardio-pulmonary and renal systems (8).

\section{Ser311Cys polymorphism of DRD2}

We performed PCR-direct sequencing and singlestrand conformation polymorphism (SSCP) analysis of $D R D 2$ using 50 unrelated Japanese patients with schizophrenia and 110 controls. Patients were diagnosed by two experienced psychiatrists according to the Diagnostic and Statistical Manual of Mental Disorders (DSM-III-R) criteria for schizophrenia. This study was approved by the ethics committee of Tokyo Medical and Dental University. Written informed consent was obtained according to the research protocol from all subjects prior to enrollment in this study.

We detected three nucleotide changes: rs6275, rs6277, and rs 1801028 . Of these, rs6275 and rs6277 have already been reported and are same-sense polymorphisms resulting in $\mathrm{His}^{313}$ and $\mathrm{Pro}^{319}$, respectively. However, rs1801028 was a novel missense nucleotide change causing an amino acid substitution of cysteine in the place of serine at codon 311 (9) (Fig. 1). Five of the 110 controls were found to be heterozygous for Ser311Cys. The allele frequency of Cys 311 in controls was 0.025 , indicating that this variant is polymorphic among Japanese individuals. In comparison, 4 of the 50 schizophrenic subjects were heterozygous for Ser311Cys, with an allele frequency of 0.08. The prevalence of subjects with Cys 311 tended to

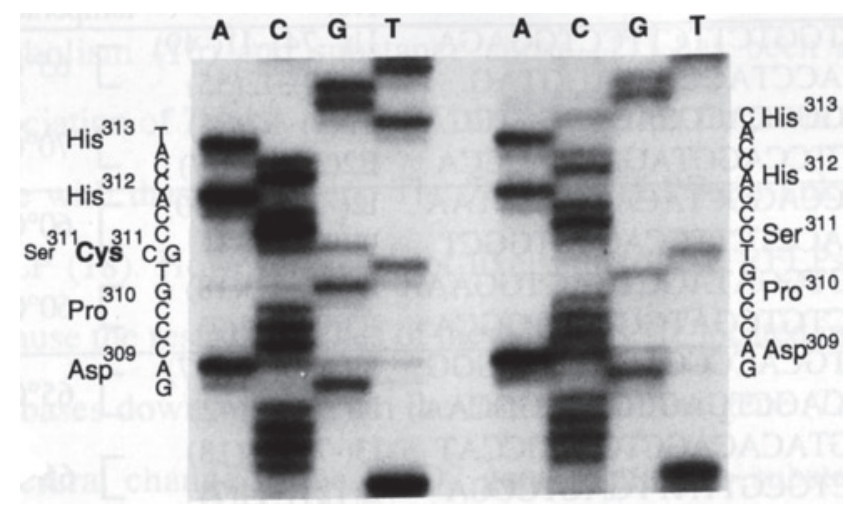

Fig. 1. Nucleotide sequences for a portion of exon 7 in the DRD2 gene from a subject heterozygous for Ser311Cys (left) and a subject homozygous for Ser311 (right). In addition, these subjects were homozygous for CAC (right) and CAT (left) at codon 313. Reproduced from Ref. 9 with permission. be slightly higher in schizophrenia than in controls, but no significant differences in genotypic or allelic frequencies were apparent. The 4 patients with Cys 311 tended to show relatively younger age of onset $(21.8 \pm 0.9$ years $)$ as compared to the 46 patients showing schizophrenia without Cys311 (27.2 \pm 1.5 years), although the difference was not significant. Three of the 4 schizophrenia patients carrying Cys 311 and 10 of 46 patients who were homozygous for Ser311 showed first-degree family history, indicating that Cys 311 is significantly associated with positive family history $\left(\chi^{2}=5.42, \mathrm{df}=1, P=0.019\right.$, odds ratio $(\mathrm{OR})=10.8,95 \%$ confidence interval $(\mathrm{CI})$ $=1.01-115.4)(9)$.

We next expanded the sample size to 156 patients with schizophrenia and 300 controls to perform an association study. Genotyping was performed using only the polymerase chain reaction (PCR) method; a modified primer was used to create a restriction fragment length polymorphism indicative of the variant gene, introducing an artificial restriction site for $A s u \mathrm{I}$ in the Ser311 allele.

We detected 14 Cys 311 carriers with schizophrenia, including 3 homozygotes, and 11 controls heterozygous for Cys311. The allele frequency of Cys311 was significantly higher in individuals with schizophrenia than in controls $\left(\chi^{2}=9.01, \quad \mathrm{df}=1, \quad P=0.002, \quad \mathrm{OR}=3.08\right.$, $95 \% \mathrm{CI}=1.42-6.67)(10)$. The homozygotes we found were not offspring of consanguineous marriages. Four $(18 \%)$ of the 22 parents of heterozygous individuals with schizophrenia had been treated for schizophrenia, compared with 11 (4\%) of 284 parents of Ser311 homozygous patients, according to hospital records $\left(\chi^{2}=8.96, \mathrm{df}=1\right.$, $P=0.002, \mathrm{OR}=5.51,95 \% \mathrm{CI}=1.59-19.1) . \mathrm{We}$ also found a significantly high frequency of Cys311 in patients showing disease onset before 25 years of age, with $76(53 \%)$ of 142 homozygous Ser311 and $13(92 \%)$ of 14 Cys311 carriers $\left(\chi^{2}=8.04, \mathrm{df}=1, P=0.004, \mathrm{OR}=11.2\right.$, $95 \% \mathrm{CI}=1.43-88.6)$. We assessed total duration of admission as the ratio of total years of admission to years from onset to time of the study. The ratio was 0.67 in Ser311 homozygotes, 0.37 in heterozygotes, and 0.11 in Cys311 homozygotes, suggesting an association of Cys311 with short duration of hospitalization $(P<0.0001$, one-way analysis of variance). Symptom severity was measured using the Manchester scale, with incoherence and irrelevance of speech $(P=0.022)$, flattened, incongruous affect $(P=0.006)$, and psychomotor retardation $(P=0.045)$ showing significantly lower scores in Cys 311 carriers than in those without this allele (10). Most patients with Cys 311 were classified as showing either catatonic-type or paranoid-type schizophrenia. Features in these patients were consistent with the type I syndrome of schizophrenia proposed by Crow (11), for which an association with a change in dopaminergic transmission 
has been suggested.

We again expanded samples to 291 cases of schizophrenia (including 11 postmortem brain samples), 579 controls, and 78 cases of affective disorder in a further case-control study (12). We assessed clinical symptoms of expanded samples using the Manchester scale. Positive symptoms were assessed by items of delusions and hallucinations, and negative symptoms were assessed by items of poverty of speech, affective flattening, or psychomotor retardation according to the scale. Presence of positive or negative symptoms was defined as a morbid rating $(2,3$, or 4$)$ for at least one of these items. Cys311 was found in $15(18 \%)$ of 83 cases of schizophrenia with absence of negative symptoms, representing a significantly higher frequency than the $24(4.1 \%)$ of 579 controls $\left(\chi^{2}=25.39, \mathrm{df}=1, P<0.00001, \quad \mathrm{OR}=5.1\right.$, $95 \% \mathrm{CI}=2.55-10.1)(12)$. However, the prevalence of Cys311-positive patients with negative symptoms ( 9 of 197 patients, $4.5 \%$ ) was similar to that of controls $\left(\chi^{2}=0.01, \mathrm{df}=1, P=0.89, \mathrm{OR}=1.05,95 \% \mathrm{CI}=0.48-\right.$ 2.31). To evaluate interpersonal aspects of the psychopathology of schizophrenia, present marital status was compared in those patients $>30$-year-old according to hospital records. Eight $(21 \%)$ of 38 married patients with schizophrenia and $7(6.6 \%)$ of 106 unmarried patients with schizophrenia carried a Cys311 allele. Of note was the finding that Ser311Cys-positive patients were more frequently married when compared with Ser311Cysnegative patients $\left(\chi^{2}=3.25, \mathrm{df}=1, P=0.01, \mathrm{OR}=3.77\right.$, $95 \% \mathrm{CI}=1.26-11.2)$. These data suggest less-severe interpersonal impairment in Ser311Cys-positive schizophrenia, particularly in those lacking negative symptoms (12).

Our data suggest that Cys311-positive schizophrenia may respond well to treatment and thus shows a lower frequency of negative symptoms and interpersonal impairment. Lane et al. (13) supported the features of the patients with Cys311. They assessed changes in clinical manifestations for 123 patients with schizophrenia, including 12 patients carrying Cys311, over the course of 42 days of treatment with resperidone. Cys311-positive patients showed significant improvements with a larger change in scores for negative symptoms as measured by PANSS (positive and negative syndrome scale) when compared to Cys311-negative patients with schizophrenia.

Patients with affective disorders comprised 34 patients with bipolar disorder, 33 patients with major depression, and 11 patients with dysthymia. Of these, $6(7.7 \%)$ of 78 patients with affective disorders were Cys311 carriers, showing an allele frequency not significantly different compared to controls. However, frequency of the allele was significantly higher in patients showing bipolar disorder with mood-incongruent psychosis as compared to controls $\left(\chi^{2}=17.2, \mathrm{df}=1, P=0.006, \quad \mathrm{OR}=11.5\right.$, $95 \% \mathrm{CI}=2.72-49.0)(12)$. These data suggest that Ser311Cys might be one factor associated with positive symptoms of schizophrenia or other symptomatic dimensions of schizophrenia.

\section{Agonist-induced sequestration of $D_{2}$ receptor}

Both $\mathrm{D}_{2}$ receptors and muscarinic receptors are characterized by long third intracellular loops. The third cytoplasmic loops of muscarinic receptors have been indicated to be involved in receptor down-regulation (14) and sequestration (15). We investigated the effects of Ser311Cys on sequestration of the $\mathrm{D}_{2}$ receptor, since the variant substitution is located in the middle portion of the third intracellular loop. We stably expressed cDNAs of DRD 2 containing Ser 311 or Cys 311 in CHO (Chinese hamster ovary) cells and examined sequestration as the reversible loss of $\left[{ }^{3} \mathrm{H}\right]$ sulpiride binding sites from the cell surface. The rate of decrease in $\left[{ }^{3} \mathrm{H}\right]$ sulpiride binding activity tended to be slower for Cys311-type $\mathrm{D}_{2}$ receptor $\left(t_{1 / 2}=24.9 \pm 7.8 \mathrm{~min}\right)$ than for Ser311-type $\mathrm{D}_{2}$ receptor $\left(t_{1 / 2}=18.7 \pm 1.6 \mathrm{~min}\right)$, but the difference was not significant. The $\left[{ }^{3} \mathrm{H}\right]$ sulpiride binding activity decreased $38.2 \pm$ $4.1 \%$ for mutant $\mathrm{D}_{2}$ receptors treated with $10^{-4} \mathrm{M}$ dopamine for $30 \mathrm{~min}$, a value significantly lower than the corresponding value of $49.1 \pm 7.1 \%$ obtained for wildtype $\mathrm{D}_{2}$ receptors $(P<0.005)$ (Fig. 2) (16). Significant differences in the proportion of decreased $\left[{ }^{3} \mathrm{H}\right]$ sulpiride binding activity between Ser311- and Cys311-type $\mathrm{D}_{2}$ receptors were also detected using treatment with $10^{-5}$, $10^{-6}$, or $10^{-7} \mathrm{M}$ dopamine. The concentration of dopamine

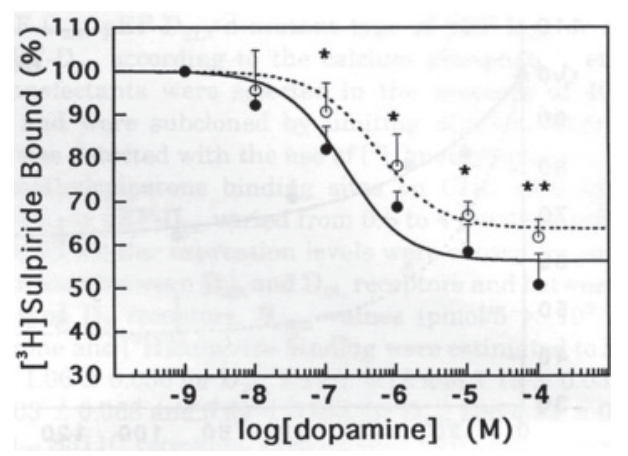

Fig. 2. Comparison between Ser311 and Cys311-type $D_{2}$ receptors. CHO cells expressing Ser311 (closed circle) or Cys311-type (open circle) $D_{2}$ receptors were incubated with the indicated concentrations of dopamine for $30 \mathrm{~min}$ and then subjected to $\left[{ }^{3} \mathrm{H}\right]$ sulpiride binding assays at $4^{\circ} \mathrm{C}$ for $4 \mathrm{~h}$. Results for $\mathrm{D}_{2}$ receptors are shown as the mean \pm S.D. from 10 independent experiments assayed in triplicate. Dose-response curves for averaged values were fitted to the following equation: $R_{\max } \times \mathrm{EC}_{50} /\left(\mathrm{EC}_{50}+[\right.$ dopamine $\left.]\right)+\left(100-R_{\max }\right)$. Reproduced from Ref. 16 with permission. ${ }^{*} P<0.05, * * P<0.01$. 
yielding half-maximal effect was estimated to be $930 \pm 930 \mathrm{nM}$ for mutant $\mathrm{D}_{2}$ receptors and $250 \pm 150 \mathrm{nM}$ for the wild-type, representing a significant difference $(P<0.05)$. This was not due to a difference in affinity for dopamine between Ser311- and Cys311-type $\mathrm{D}_{2}$ receptors, as no differences were identified in affinities to dopaminergic ligands, including dopamine, between these two receptors expressed in COS-7. In these experiments, binding affinity was assessed by the displacement of $\left[{ }^{3} \mathrm{H}\right]$ sulpiride binding to membrane preparations (data not shown). If the sequestration of $\mathrm{D}_{2}$ receptors contributes to desensitization (17), the Cys311-type $\mathrm{D}_{2}$ receptor will show impaired ability to decrease the response to continuous dopaminergic stimulation, consistent with the dopamine hypothesis.
Al-Fulaij et al. (18) expressed cDNAs of DRD2 with various variations including Ser311Cys in HEK293 or neuronal GT1 cells and determined basal and ligand-induced signaling for each of these receptors compared to wild-type. Significantly higher levels of ropinirole were found to induce maximal effects of $\mathrm{D}_{2}$ receptor with Cys311 compared to wild-type. These data also support the idea that Cys311 provides hyper-dopaminergic transmission.

\section{Meta-analysis for association of Ser311Cys with schizophrenia}

Glatt et al. (19) performed the first meta-analysis for associations of Ser311Cys with schizophrenia using 24

SZGene meta-analysis for DRD2 (rs1801028): G vs. C

\begin{tabular}{|c|c|c|}
\hline All studies & $\begin{array}{r}\text { OR } \\
1.21\end{array}$ & $\begin{array}{r}95 \% \mathrm{Cl} \\
{[1.02,1.45]}\end{array}$ \\
\hline All excl initial & 1.21 & {$[1.01,1.45]$} \\
\hline Caucasian studies & 1.33 & {$[0.94,1.89]$} \\
\hline Asian studies & 1.33 & {$[1.03,1.72]$} \\
\hline Asian excl initial & 1.31 & {$[1.01,1.70]$} \\
\hline \multicolumn{3}{|l|}{ Study specific ORs } \\
\hline Dubertret, 2010 [C] & 0.99 & {$[0.28,3.53]$} \\
\hline Srivastava, $2010[0] \dagger$ & - & - \\
\hline Fan, 2009 [A] & 1.27 & {$[0.74,2.15]$} \\
\hline Gupta, $2009[0]$ & 1.09 & {$[0.70,1.70]$} \\
\hline Sanders, $2008[\mathrm{C}]$ & 0.74 & {$[0.55,1.01]$} \\
\hline Vijayan, 2007 [0] & 1.02 & {$[0.65,1.62]$} \\
\hline Hall, $2007[\mathrm{C}] \ddagger$ & - & - \\
\hline Dubertret, $2004[\mathrm{C}]$ & 1.63 & {$[0.39,6.81]$} \\
\hline Jonsson, $2003[\mathrm{C}]$ & 4.93 & {$[1.57,15.47]$} \\
\hline Morimoto, 2002 [A] & 1.00 & {$[0.30,3.30]$} \\
\hline Himei, 2002 [A] & 1.37 & {$[0.51,3.66]$} \\
\hline Hori, 2001 [A] & 1.32 & {$[0.69,2.54]$} \\
\hline Serretti, $2000[C]$ & 1.84 & {$[0.99,3.43]$} \\
\hline Spurlock, 1998, Austria [C] & 0.19 & {$[0.02,1.83]$} \\
\hline Spurlock, 1998, Ireland [C] & 0.65 & {$[0.07,6.19]$} \\
\hline Spurlock, 1998, Italy [C] & 2.11 & {$[0.70,6.33]$} \\
\hline Spurlock, 1998, UK [C] & 0.54 & {$[0.05,6.35]$} \\
\hline Kaneshima, $1997[\mathrm{~A}]$ & 0.82 & {$[0.23,2.91]$} \\
\hline Harano, $1997[\mathrm{~A}]$ & 1.47 & {$[0.53,4.10]$} \\
\hline Fujiwara, 1997 [A] & 1.00 & {$[0.08,11.86]$} \\
\hline Verga, $1997[\mathrm{C}]$ & 2.13 & {$[0.71,6.39]$} \\
\hline Ohara, $1996[\mathrm{~A}]$ & 0.26 & {$[0.03,2.65]$} \\
\hline Crawford, 1996 [C] & 2.30 & {$[0.57,9.33]$} \\
\hline Chen, 1996 [A] & 0.61 & {$[0.16,2.37]$} \\
\hline Sasaki, 1996 [C] & 1.02 & {$[0.44,2.37]$} \\
\hline Tanaka, 1996 [A] & 1.13 & {$[0.42,3.05]$} \\
\hline Arinami, 1996 [A] & 2.51 & {$[1.36,4.63]$} \\
\hline Pal, $1995[0] \dagger$ & - & - \\
\hline Gejman, 1994 [O] & 0.88 & {$[0.19,4.11]$} \\
\hline Sobell, 1994 [C] & 1.01 & {$[0.54,1.91]$} \\
\hline Hattori, 1994 [A] & 0.87 & {$[0.30,2.50]$} \\
\hline Nothen, $1994[\mathrm{C}]$ & 0.61 & {$[0.16,2.37]$} \\
\hline Shaikh, 1994 [C] & 5.10 & {$[0.60,43.64]$} \\
\hline Asherson, 1994 [C] & 1.14 & {$[0.10,13.39]$} \\
\hline Nanko, $1994[\mathrm{~A}] \ddagger$ & - & - \\
\hline Arinami, $1994[\mathrm{~A}] \ddagger$ & - & - \\
\hline Laurent, $1994[\mathrm{C}]^{+}$ & 2.75 & {$[0.63,11.98]$} \\
\hline Itokawa, $1993[\mathrm{~A}]$. & 1.79 & {$[0.46,7.01]$} \\
\hline
\end{tabular}

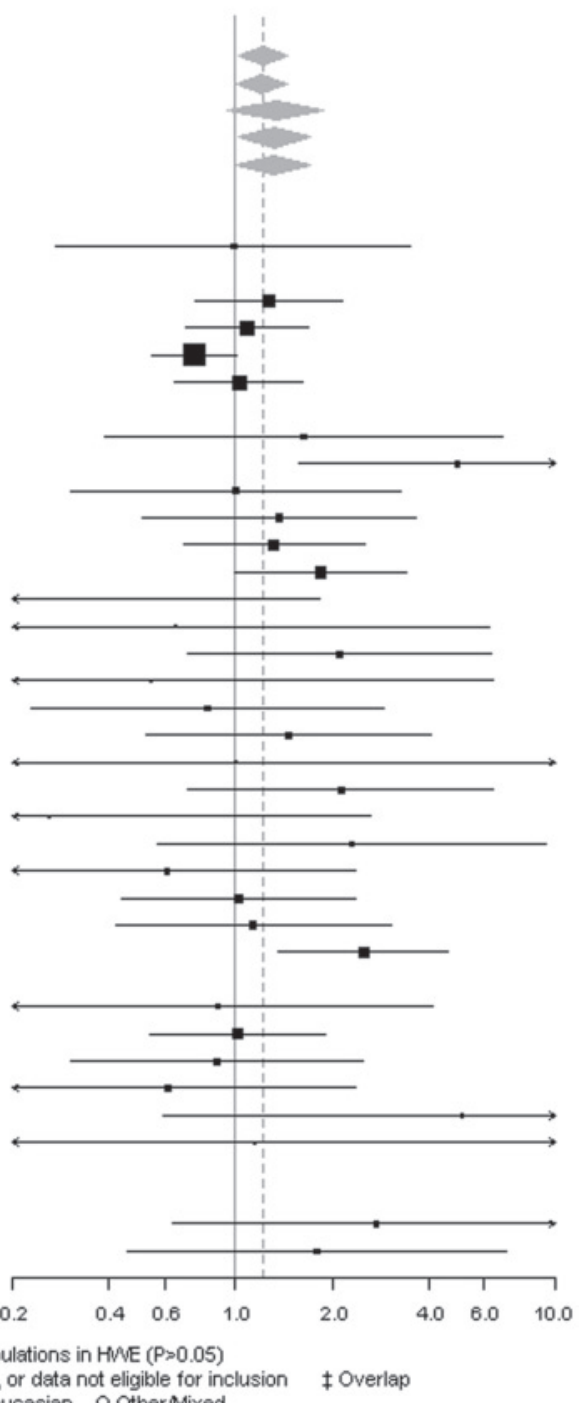

All control populations in $\mathrm{HME}(P>0.05)$

No data provided, or data not eligible for inclusion $\quad \ddagger$ Overlap

A Asian C Caucasian O OtherMixed

Fig. 3. Meta-analysis of Ser311Cys of DRD2 (22). A box shows the odds ratio and a bar indicates the $95 \%$ confidence interval. A diamond represents the odds ratio calculated by meta-analysis. 
published case-control studies (3733 cases, 5373 controls) and reported a significant association with a pooled OR of $1.3(P=0.007)$. Jönsson et al. (20) also supported such an association using 26 studies covering 3506 patients with schizophrenia and 5646 controls $(\mathrm{OR}=1.43$, $P<0.001)$. They also detected significant associations using studies with Asian patients $(\mathrm{OR}=1.42, P<0.02)$ and Caucasian patients $(\mathrm{OR}=1.42, P<0.02)$. A third meta-analysis by Glatt et al. (21) confirmed an association using 27 published studies, comprising 3707 cases and 5363 control subjects. They reported a significant effect of the Cys allele on schizophrenia risk observed under fixed-effects $(\mathrm{OR}=1.38, P=0.002)$ and randomeffects $(\mathrm{OR}=1.36, P=0.007)$ models. Furthermore, they performed a genotype-based meta-analysis and found that homozygotes for Cys311 were not at any elevated risk relative to heterozygotes under either fixed-effects $(\mathrm{OR}=1.03, P=0.95)$ or random-effects $(\mathrm{OR}=0.96, P=0.94)$ models. This suggests that the Cys311 allele has a dominant effect on disease risk. SchizophreniaGene (SZGene) database also confirmed the association between the polymorphism and schizophrenia (Fig. 3) (22).

\section{Conclusion}

The Ser311Cys polymorphism in DRD2 was found to be associated with schizophrenia. Patients with the Cys 311 allele show a shorter duration of hospitalization, less severe negative symptoms, and higher frequency of being married compared to patients without this allele, suggesting good treatment response. In vitro studies suggest that the Cys311-type $\mathrm{D}_{2}$ receptor impairs dopamineinduced sequestration, consistent with the dopamine hypothesis.

\section{Acknowledgment}

This study was supported by a grant from the National Center of Neurology and Psychiatry of the Ministry of Health and Welfare, Japan.

\section{References}

1 Sullivan PF, Kendler KS, Neale MC. Schizophrenia as a complex trait: evidence from a meta-analysis of twin studies. Arch Gen Psychiatry. 2003;60:1187-1192.

2 Sullivan PF. The genetics of schizophrenia. PLoS Med. 2005;2: e212.

3 Angrist BM, Gershon S. The phenomenology of experimentally induced amphetamine psychosis--preliminary observations. Biol Psychiatry. 1970;2:95-107.

4 Seeman P, Lee T, Chau-wong M, Wong K. Antipsychotic drug doses and neuroleptic/dopamine receptors. Nature. 1976;261: 717-719.
5 Marzella PL, Copolov D. [3H]nemonapride binding in human caudate and putamen. Brain Res Bull. 1997;44:167-170.

6 Seeman P, Guan HC, Van Tol HH. Dopamine D4 receptors elevated in schizophrenia. Nature. 1993;365:441-445.

7 Sullivan PF, Kendler KS, Neale MC. Schizophrenia as a complex trait: evidence from a meta-analysis of twin studies. Arch Gen Psychiatry. 2003;60:1187-1192.

8 Hashimoto K, Oyama T, Sugiyama T, Park Y, Kurita T. Neuronal excitation in the ventral tegmental area modulates the micturition reflex mediated via the dopamine $\mathrm{D}_{1}$ and $\mathrm{D}_{2}$ receptors in rats. J Pharmacol Sci. 2003;92:143-148.

9 Itokawa M, Arinami T, Futamura N, Hamaguchi H, Toru M. A structural polymorphism of human dopamine D2 receptor, D2(Ser311-->Cys). Biochem Biophys Res Commun. 1993;196: 1369-1375.

10 Arinami T, Itokawa M, Enguchi H, Tagaya H, Yano S, Shimizu $\mathrm{H}$, et al. Association of dopamine D2 receptor molecular variant with schizophrenia. Lancet. 1994;343:703-704.

11 Crow TJ. Molecular pathology of schizophrenia: more than one disease process? Br Med J. 1980;280:66-68.

12 Arinami T, Itokawa M, Aoki J, Shibuya H, Ookubo Y, Iwawaki A, et al. Further association study on dopamine D2 receptor variant S311C in schizophrenia and affective disorders. Am J Med Genet. 1996;67:133-138.

13 Lane HY, Lee CC, Chang YC, Lu CT, Huang CH, Chang WH. Effects of dopamine D2 receptor Ser311Cys polymorphism and clinical factors on risperidone efficacy for positive and negative symptoms and social function. Int $\mathrm{J}$ Neuropsychopharmacol. 2004;7:461-470.

14 Shapiro RA, Nathanson NM. Deletion analysis of the mouse m1 muscarinic acetylcholine receptor: effects on phosphoinositide metabolism and down-regulation. Biochemistry. 1989;28:89468950.

15 Maeda S, Lameh J, Mallet WG, Philip M, Ramachandran J, Sadée W. Internalization of the Hm1 muscarinic cholinergic receptor involves the third cytoplasmic loop. FEBS Lett. 1990; 269:386-388.

16 Itokawa M, Toru M, Ito K, Tsuga H, Kameyama K, Haga T, et al. Sequestration of the short and long isoforms of dopamine D2 receptors expressed in Chinese hamster ovary cells. Mol Pharmacol. 1996;49:560-566.

17 Hausdorff WP, Caron MG, Lefkowitz RJ. Turning off the signal: desensitization of beta-adrenergic receptor function. FASEB J. 1990;4:2881-2889.

18 Al-Fulaij MA, Ren Y, Beinborn M, Kopin AS. Pharmacological analysis of human D1 AND D2 dopamine receptor missense variants. J Mol Neurosci. 2008;34:211-223.

19 Glatt SJ, Faraone SV, Tsuang MT. Meta-analysis identifies an association between the dopamine D2 receptor gene and schizophrenia. Mol Psychiatry. 2003;8:911-915.

20 Jönsson EG, Sillén A, Vares M, Ekholm B, Terenius L, Sedvall GC. Dopamine D2 receptor gene Ser311Cys variant and schizophrenia: association study and meta-analysis. Am J Med Genet B Neuropsychiatr Genet. 2003;119B:28-34.

21 Glatt SJ, Jönsson EG. The Cys allele of the DRD2 Ser311Cys polymorphism has a dominant effect on risk for schizophrenia: evidence from fixed- and random-effects meta-analyses. Am J Med Genet B Neuropsychiatr Genet. 2006;141B:149-154.

22 SchizophreniaGene (SZGene) http://www.schizophreniaforum. org/res/sczgene/default.asp 